BMJ Open Sport \& Exercise Medicine

\section{Concussion with primary impact to the chest and the potential role of neck tension}

To cite: Jadischke R, Viano DC, McCarthy J, et al. Concussion with primary impact to the chest and the potential role of neck tension. BMJ Open Sport \& Exercise Medicine 2018;4:e000362. doi:10.1136/ bmjsem-2018-000362

- Additional material is published online only. To view please visit the journal online (http://dx.doi.org/10.1136/ bmjsem-2018-000362).

Accepted 29 August 2018

\section{ABSTRACT}

Objectives Most biomechanical research on brain injury focuses on direct blows to the head. There are a few older studies that indicate craniocervical stretch could be a factor in concussion by causing strain in the upper spinal cord and brainstem. The objectives of this study are to assess the biomechanical response and estimate the strain in the upper cervical spine and brainstem from primary impact to the chest in American football.

Methods Impact testing was conducted to the chest of a stationary unhelmeted and helmeted anthropomorphic test device (ATD) as well as the laboratory reconstruction of two NFL game collisions resulting in concussion. A finite element (FE) study was also conducted to estimate the elongation of the cervical spine under tensile and flexion loading conditions.

Results The helmeted ATD had a 40\% ( $t=9.84, p<0.001)$ increase in neck tensile force and an $8 \%(t=7.267$, $\mathrm{p}<0.001$ ) increase in neck flexion angle when compared with an unhelmeted ATD. The case studies indicated that the neck tension in the injured players exceeded tolerable levels from volunteer studies. The neck tension was combined with flexion of the head relative to the torso. The FE analysis, combined with a spinal cord coupling ratio, estimated that the strain along the axis of the upper cervical spinal cord and brainstem was 10\%-20\% for the combined flexion and tension loading in the two cases presented.

Conclusion Strain in the upper spinal cord and brainstem from neck tension is a factor in concussion.

\section{BACKGROUND}

The 2012 consensus statement on concussion (c) Author(s) (or their employer(s)) 2018. Re-use permitted under CC BY. Published by BMJ.

${ }^{1}$ McCarthy Engineering, Windsor, Ontario, Canada

${ }^{2}$ Department of Biomedical Engineering, Wayne State University, Detroit, Michigan, USA

${ }^{3}$ ProBiomechanics, Bloomfield Hills, Michigan, USA

Correspondence to Ron Jadischke; ronjadischke@ yahoo.ca in sport included the statement that 'concussion may be caused by a direct blow to the head, face, neck or elsewhere on the body with an impulsive force transmitted to the head. ${ }^{1}$ There are few studies on concussion with primary impact to the chest and the study of this type of collision may shed some light on a mechanism of injury.

In animal testing, Friede ${ }^{2} 3$ studied the mechanics of concussion by evaluating the signs and neuropathology in the upper spinal cord and brainstem of cats in response to a distraction load in a non-impact condition. He concluded that craniocervical
What are the new findings?

There has not been much recent focus on the potential importance of neck tension causing concussion.

- The mass of a helmet added to a head can result in increased neck tension forces in impacts primarily to the chest.

- Compared with direct helmet-to-helmet collisions causing concussion, these impacts primarily to the chest result in lower head accelerations and angular velocities.

- Neck tension or strain along the axis of the upper cervical spinal cord and brainstem is a possible mechanism of brain injury and should be considered in the design and evaluation of helmets.

How might it impact on clinical practice in the near future?

These findings could help identify a mechanism of concussion in sport.

- These data could be used by helmet manufacturers to develop protective equipment to reduce the incidence of concussion in sport and also methods to treat injured athletes.

distraction (tension) and flexion are the most important factors in concussion. Ommaya et $a l^{t}$ produced signs of cerebral concussion, haemorrhages on and contusions over the surface of the brain and upper cervical cord by rotational displacement of the head on the neck, without direct head impact. They concluded that multiple mechanisms are involved in cerebral concussion, among them are rotational acceleration of the head, flexion-extension-tension of the neck and intracranial pressure gradients. Hodgson ${ }^{5}$ concluded that relative movement at the craniocervical junction may be an important factor in whether there is loss of consciousness in impacts resulting in inertial loading of the head.

In the human, sled testing conducted by Col John P Stapp ${ }^{6}$ resulted in the loss of consciousness of one volunteer at a peak sled 
deceleration of $38 \mathrm{~g}$ with an onset rate of $1370 \mathrm{~g} / \mathrm{s}$ without impact to the head. Hutchinson ${ }^{7}$ conducted a video analysis of 174 concussion-causing hits in the NHL. Twenty per cent of these injuries had a primary shoulder-to-chest contact, but less than $5 \%$ had no secondary head contact. King $e t a l^{8}$ used a discrete parameter model of the head and neck to study the response of the neck of pilots who ditch in the ocean and fail to eject before the jet aircraft sank. Results showed that, with the added weight of a helmet, one of the reasons for the pilots failing to eject was cord concussion due in part to upper cervical cord stretch during the combined vertical acceleration and forward deceleration of the aircraft. The computed head linear and angular accelerations were below concussive levels. Ommaya, ${ }^{9} \operatorname{Hodgson}^{5}$ and Jadischke et $a l^{10}$ also indicated that the mass of the helmet aggravates the potential for injury by adding bending, axial and shear loads at the craniocervical junction.

The objective of this study was to assess the biomechanical responses from impact to the chest in American football. This study was completed in three phases. First, impact testing was conducted to the chest of a stationary anthropomorphic test device (ATD), both helmeted and unhelmeted. Second, a case study of two NFL game collisions was conducted to estimate the biomechanical forces in real-life collisions resulting in concussion. In these cases, the primary impact was to the chest, and the player experienced a concussion with a delayed return to play. Third, a finite element (FE) study was conducted using the head and neck from the Global Human Body Model Consortium (GHBMC) Average Male model to estimate the strain along the axis of the cervical spinal cord and brainstem under combined tensile and flexion loading conditions.

\section{MATERIALS AND METHODS}

\section{Test series 1: general impact testing}

Impact tests were conducted with head, neck and upper torso of a Hybrid III 50th percentile ATD struck at the centre of gravity of the chest. The $14 \mathrm{~kg}$ pelvis of the ATD was replaced with a $13 \mathrm{~kg}$ steel base. The ATD lumbar spine was vertical and the ATD was placed on a height-adjustable table. The tests were conducted by striking the stationary ATD with a $45 \mathrm{~kg}$ impactor with a $38.1 \mathrm{~mm}(1.5$ inch) thick deformable vinyl nitrile end cap at impact speeds of $5-10 \mathrm{~m} / \mathrm{s}$. This end cap is used commonly in helmet-to-helmet testing to simulate a helmeted player. ${ }^{11}$ The impacts were repeated back-to-back with the ATD helmeted and unhelmeted. In the 9 and $10 \mathrm{~m} / \mathrm{s}$ impacts, the facemask was removed to prevent it from striking the impactor ram. Details regarding the ATD instrumentation and filtering are found in the online supplementary figure $\mathrm{S} 1$. The ratio of the biomechanical responses from the ATD in the helmeted condition versus the unhelmeted condition was compared using a one-sided Student's t-test.

\section{Test series 2: laboratory reconstructions}

Game video was analysed to assess the heading angles, torso angles and closing speeds of two cases in the NFL with primary impact to the chest that resulted in concussion. The independent analyses from multiple camera views resulted in the estimated helmet location overlaying each other when plotted in three-dimensional (3D) model of the playing field. The scaled model of the playing field, distance travelled by the player's helmet and the time between frames were used to estimate the preimpact speed and heading angle of each of the players. The players' speeds were also checked using a two-dimensional analysis of the markings on the playing field. The helmet delta-V was calculated graphically (vector subtraction) using the average speed and 3D heading angle for $0.1 \mathrm{~s}$ prior to impact and $0.1 \mathrm{~s}$ after impact.

In the laboratory, the upper bodies of two Hybrid III 50 th percentile ATDs were used to represent the football players involved in these collisions. The ATDs consisted of the Hybrid III head, neck, upper torso, shoulders, standing lumbar spine and pelvis and were ballasted using a weight vest to represent the player's upper body mass. A nylon stocking was placed over the Hybrid III headforms to reduce the friction at the head-helmet interface and to provide a more realistic response of the helmet on the headform. This is consistent with NFL helmet testing. ${ }^{12} 13$ A large-sized American football helmet weighing 2.15 $\mathrm{kg}$ was fitted onto the ATD headform representing the player struck in the chest, and a large-sized American football helmet weighing $1.85 \mathrm{~kg}$ was fitted onto the striking ATD headform. The brow pads were positioned $2.54 \mathrm{~cm}(1 \mathrm{inch})$ above the top of the nose. The chin strap was attached so that it fit snugly over the Hybrid III chin. Data acquisition and instrumentation for each of the ATDs were similar to that described in test series 1 . Additional information is provided in the online supplementary figures S2 and S3.

\section{FE modelling}

The head and neck were segmented from the whole GHBMC 50th percentile male model at the first thoracic vertebra along with all relevant musculature and ligaments. Validation of the head and neck was previously completed by others ${ }^{14}{ }^{15}$ using cadaveric and volunteer experimental data. In the present study, the model was not used to assess tissue-level strains in the brainstem and spinal cord directly because there was no specific validation related to the brainstem and upper cervical spinal cord discussed in the literature. Rather, the kinematics of the vertebrae and skull were studied to assess the craniocervical stretch in the vertebral column in response to independently applied tensile (distraction) loading and forward flexion. These were the primary biomechanical responses of players in these impacts to the chest. The elongation of the cervical column was measured using nodes defined on the anterior, left, right and posterior sides of each cervical vertebra, and the location and orientation of the skull was monitored by tracking its centre of gravity.

The average strain in the cervical spine was assessed at the level of C1-C5 since the literature ${ }^{1617}$ has shown there 
to be caudal (downward) displacement of the spinal cord relative to the spinal column in this level and cephalad (upward) displacement of the spinal cord below this level indicating that stretch of the spinal cord (above C5) and brainstem occurs. A spinal cord coupling ratio of $0.65^{1819}$ was applied to the vertebral column strain to estimate the strain along the axis of the spinal cord and brainstem relative to vertebral body strain. The kinematics predicted by the FE simulations were compared with existing human volunteer ${ }^{1720}$ and cadaveric studies. ${ }^{21}{ }^{22}$ Additional information is provided in the online supplementary figure S3.

\section{RESULTS}

\section{Test series 1: general impact testing}

The primary ATD response to chest impact was in the sagittal plane. Table 1 illustrates the biomechanical responses for various closing velocities. There was a $40 \%$ $\pm 10 \%(\mathrm{t}=9.84, \mathrm{p}<0.001)$ increase in upper neck tensile forces when compared with unhelmeted impacts of equal severity. There was also an increase of $8 \% \pm 3 \%$ $(\mathrm{t}=7.267, \mathrm{p}<0.001)$ in head flexion angle. There was a reduction in head displacement of $18 \% \pm 4 \%$ and a reduction of rotational velocity of $18 \% \pm 6 \%$. The head motion lagged behind the torso motion to a greater extent in the helmeted impacts. The helmet mass (2.15 $\mathrm{kg})$ increased the effective mass of the headform $(4.54 \mathrm{~kg}$ $+2.15 \mathrm{~kg}$ ) by $47 \%$ when compared with the unhelmeted headform $(4.54 \mathrm{~kg})$. This resulted in significantly greater neck forces and moments when compared with the unhelmeted impacts. High-speed video of a $10 \mathrm{~m} / \mathrm{s}$ chest impact is illustrated in figure 1. Additional information is provided in the online supplementary video 1 .

\section{Test series 2: laboratory reconstructions}

The closing velocities for case A and case B were 12.6 and $9.8 \mathrm{~m} / \mathrm{s}$, respectively. The reconstruction data from the struck ATD are summarised in table 2. A comparison of the postimpact kinematics of case $\mathrm{A}$ is illustrated in figure 2. A comparison of these laboratory reconstructions to the test series 1 results for the helmeted and unhelmeted ATDs is illustrated in figure 3.

\section{FE modelling}

FE modelling indicated that the strain in the vertebral column increased linearly with head flexion or tensile loading; however, it varied along the length of the cervical spine. The average strain in the vertebral column in flexion was $0.21 \%$ strain/degree of head rotation and $4.6 \%$ strain $/ 1000 \mathrm{~N}$ of tensile load. The maximum strain in the vertebral column was predicted to occur in the upper cervical spine (C1-C2) and was $0.28 \%$ strain/ degree of head rotation and $6.5 \%$ strain $/ 1000 \mathrm{~N}$ of tensile load for flexion and tension, respectively (table 3 ).

A spinal cord coupling ratio of $0.65^{1819}$ was used to estimate the central nervous system (CNS) strain relative to vertebral body strain. A maximum strain along the axis of the spinal cord and brainstem for a flexion angle of $55^{\circ}$ was predicted to be $7.5 \%-10.0 \%$. These estimates using FE modelling were comparable to in vivo volunteer data which measured a maximum strain in the spinal cord of approximately $10.2 \%$ at a $55^{\circ}$ flexion angle. ${ }^{17}$ The average strain along the axis of the cervical spinal cord and brainstem was predicted to be $1.6 \%, 4.6 \%$ and $6.8 \%$ for neck tension loads of 500, 1500 and $2500 \mathrm{~N}$, respectively. The peak strains in the upper cervical spine (C1-C2) were predicted to be $1.3 \%, 6.0 \%$ and $11.0 \%$, respectively.

\section{DISCUSSION}

The laboratory reconstruction data for case A and case B, as well as the FE data, were used to estimate the strain along the axis of the spinal cord and brainstem in these concussed NFL players. The estimated strain was $13.0 \%-18.6 \%$ in case A and $8.7 \%-12.2 \%$ in case B due to combined tension and forward flexion. This range represents the estimated average strain (low) to the maximum strain (high). The estimated total strain accounts for the time-varying sum of the strains due to tension and flexion. The laboratory reconstruction and $\mathrm{FE}$ results indicate that the axonal strain in the spinal cord and brainstem (table 3) exceeds the levels that have been documented to cause changes in functional and structural response in spinal nerve roots when stretched in tension at varying strain rates. ${ }^{23}$ The strains are similar to those documented in in vivo tests with primates which resulted in functional changes in the spinal cord as well as changes in heart rate and respiration. ${ }^{24}$

While translational acceleration, rotational velocity and rotational acceleration of the head have been discussed as biomechanical correlates with concussion, craniocervical stretch resulting from tension and flexion in the upper cervical spine has also been reported to be an important factor in concussion. ${ }^{235}$ Neck tension and head flexion have each been shown to result in strain of the upper cervical spinal cord and the brainstem. In a study of 183 human cadavers, Breig $^{25}$ found that tension generated in the spinal cord can be transmitted from the spinal cord to the brainstem. The largest elongation occurred in the medulla oblongata, and no elongation was apparent superior to the midbrain. The reticular formation of the brainstem controls heart rate, respiration and consciousness. The loss of consciousness in one of the players in this case study is consistent with injury to the brainstem. ${ }^{2352426}$

In case A and case B, the struck Hybrid III ATD underwent $51^{\circ}$ and $46^{\circ}$ of head flexion, respectively. The forward flexion of the head was combined with neck tension as a result of the inertial loading of the head and helmet. The flexion of the head is within normal range of motion of the human for quasistatic movement; however, in the human $^{17} 18$ 27-29 and primate, ${ }^{16}$ imaging studies have reported elongation of the cervical spinal canal and cord in flexion. The FE modelling results, combined with a coupling ratio, estimate strains in the CNS of $9.3 \%$ and $8.4 \%$ as a result of forward flexion, in cases $\mathrm{A}$ and $\mathrm{B}$, respectively. These strains, by themselves, are within the range that has been documented for the human ${ }^{17}$ as part of the normal range of quasistatic flexion. 


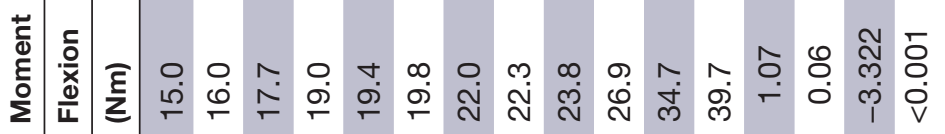

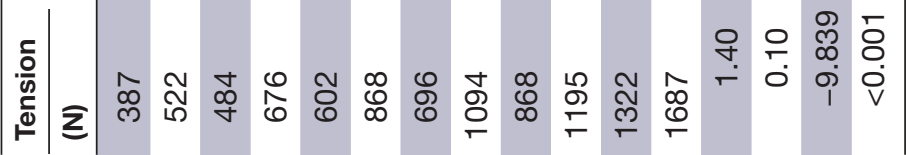

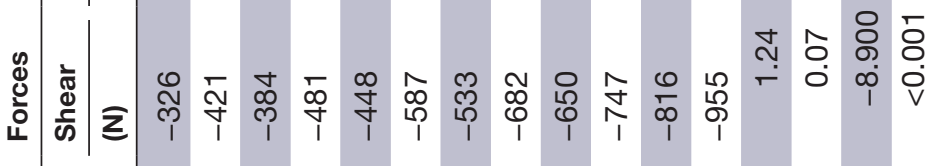

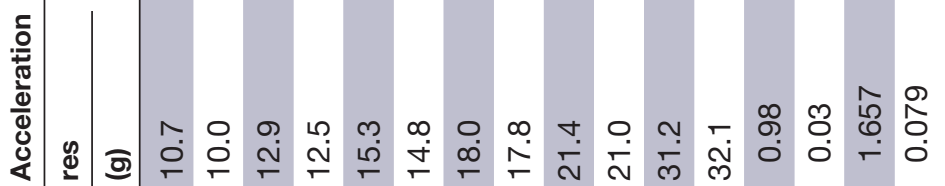

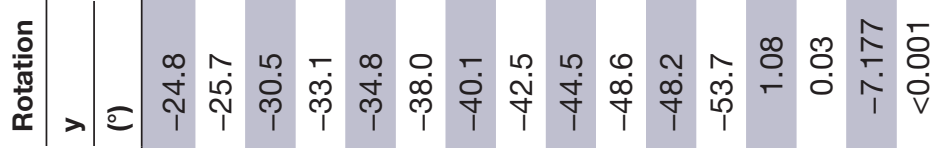

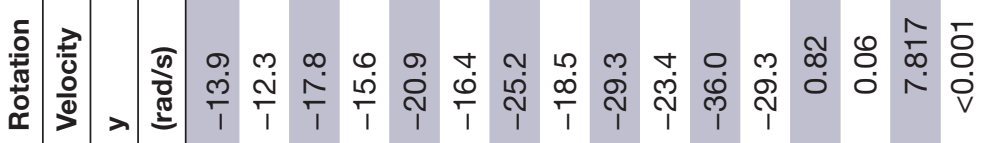

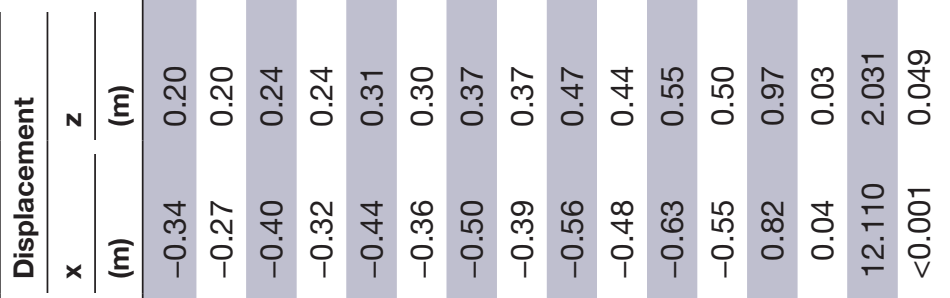

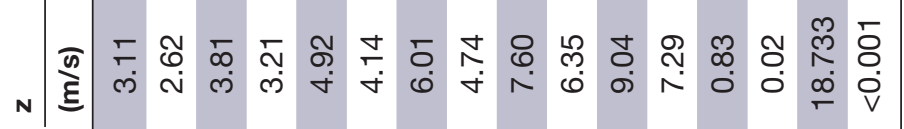

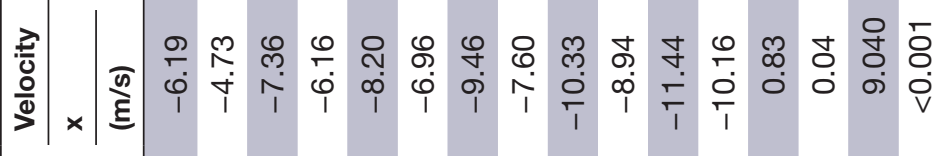

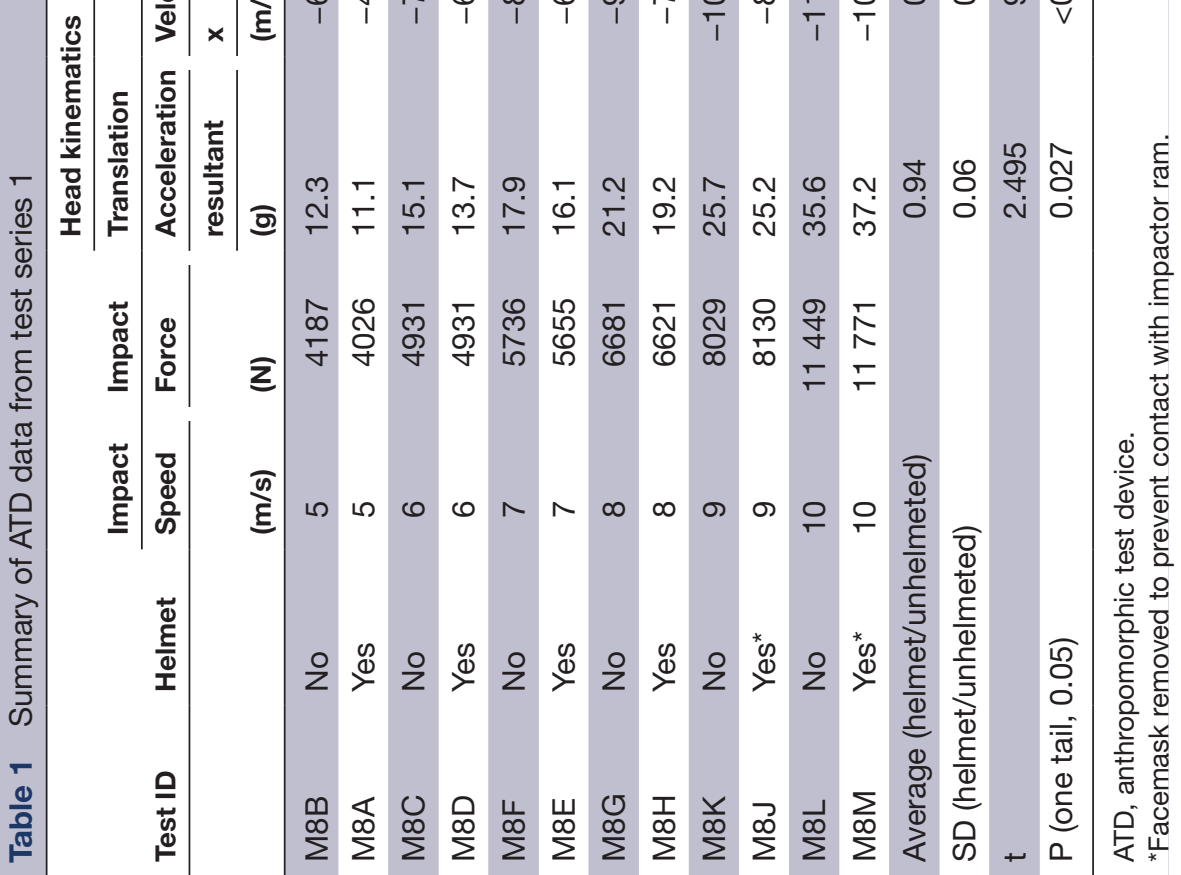



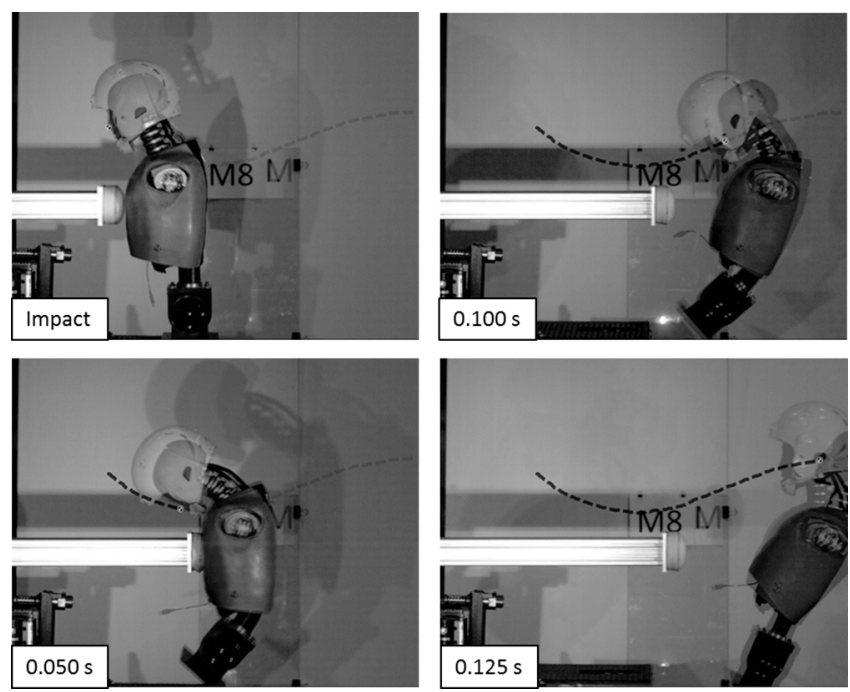

Figure 1 Comparison of a helmeted versus unhelmeted chest impact. The unhelmeted impact is overlaid onto the helmeted impact.

The neck tensions in this case study (case $\mathrm{A}=2646 \mathrm{~N}$, case $\mathrm{B}=1342 \mathrm{~N}$ ) are greater than the neck tensions found in volunteer studies ${ }^{30-32}$ and greater than uninjured NFL players $^{12}(670 \pm 405 \mathrm{~N})$. The neck tensions are similar to those reported by Viano et $a \mathrm{l}^{33}$ in their reconstruction of struck and injured players in the NFL $(1704 \pm 432 \mathrm{~N})$ and are less than the neck tensions resulting in failure of the cervical spine in musculoskeletal cadaveric studies. ${ }^{21} 223435$ The tensile loads correspond to approximately 3.27 (case A) and 1.10 (case B) times the player's body weight. This tensile load must be supported by the soft tissues of the neck. In these cases, the struck players did not appear to have the opportunity to ready themselves for the impact. From our FE study, and by applying a coupling ratio, the maximum strain in the CNS due to neck tension alone was estimated to be $11.2 \%$ and $5.7 \%$ for cases $\mathrm{A}$ and $\mathrm{B}$, respectively.

The time-varying strain along the axis of the spinal cord and brainstem due to combined tension and flexion for case A and case B was on the order of $13.0 \%$ to $18.6 \%$ and $8.7 \%$ to $12.2 \%$, respectively. The data presented in this case study support the mechanism of injury discussed
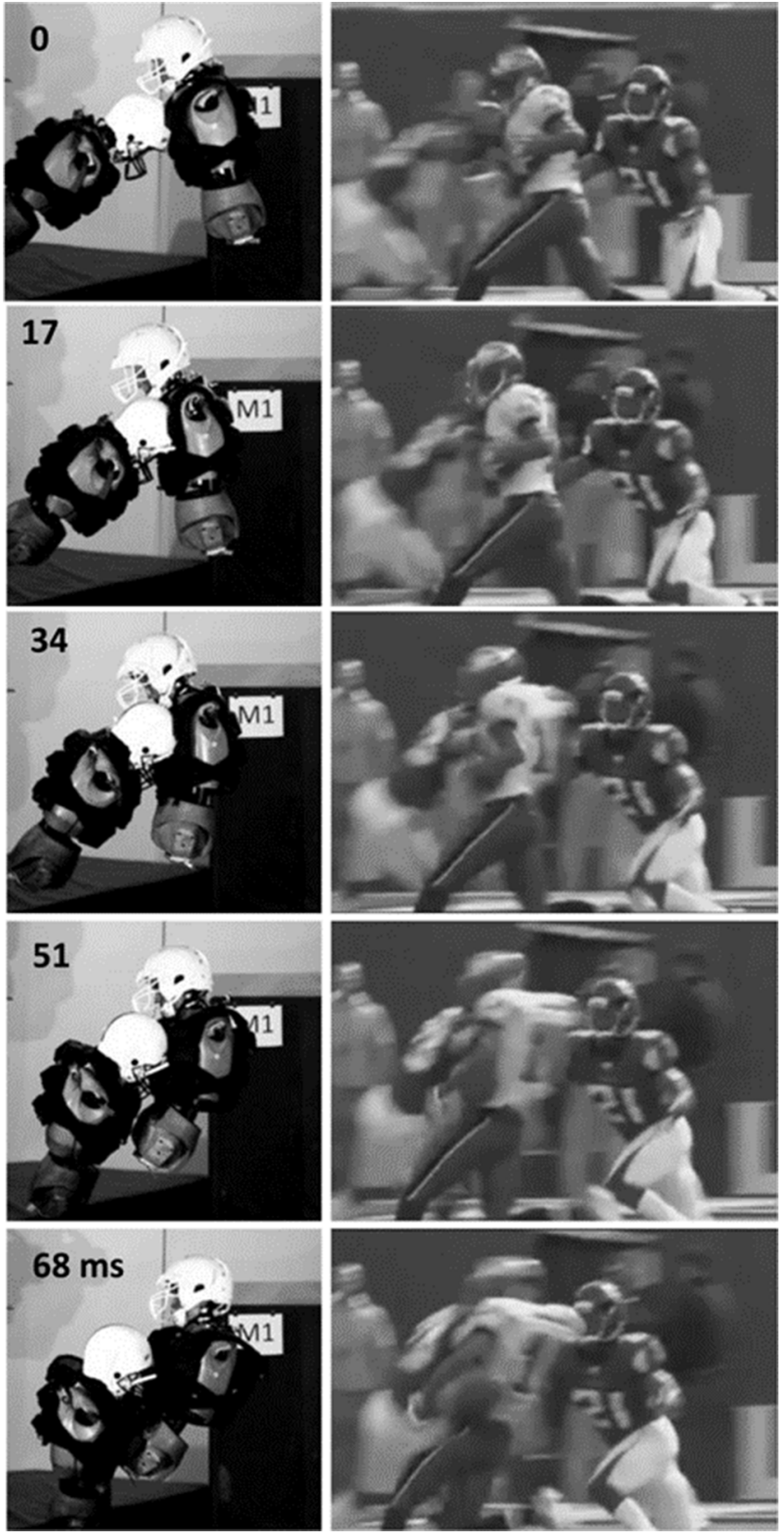

Figure 2 Comparison of the game impact for case A. 

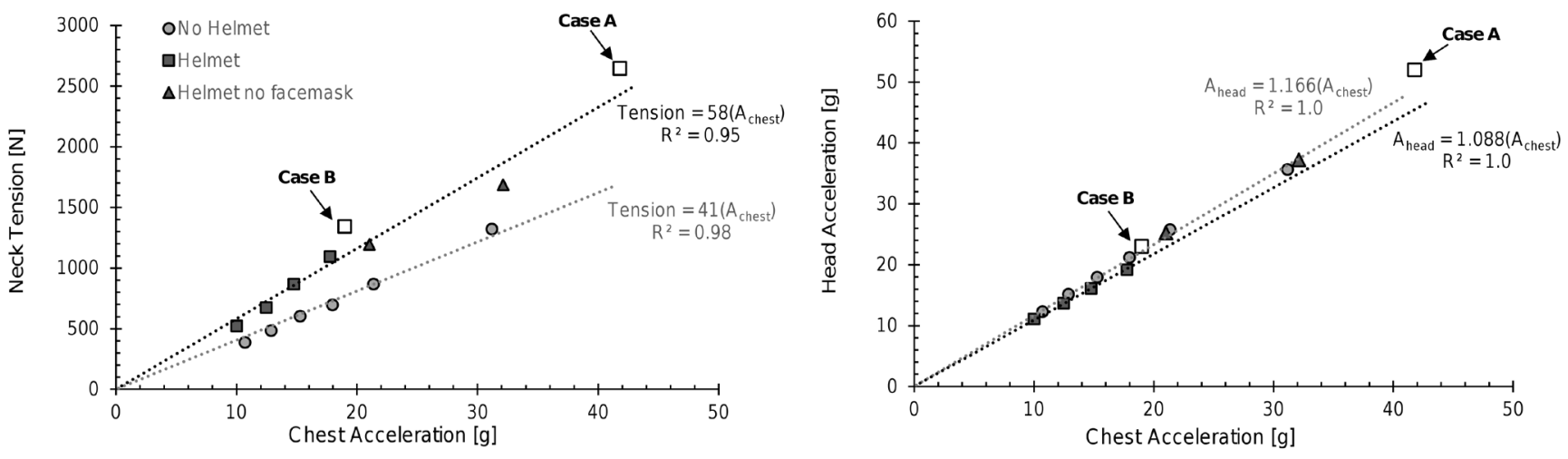

Figure 3 Neck tension and head acceleration versus chest acceleration for test series 1 and the laboratory reconstruction of case $A$ and case $B$.

by Friede ${ }^{23}$ and Hodgson and Thomas ${ }^{36}$ and Hodgson ${ }^{5}$ who have indicated that strains in the upper spinal cord and brainstem are important factors in concussion. The brainstem's relation to concussion is further supported by the early work of Denny-Brown and Russell ${ }^{26}$ who produced concussion signs in the decerebrate animal.

The addition of the helmet to the ATD headform in test series 1 resulted in an increase in neck tension and forward flexion of the head. The neck tension increased by $40 \%$ and forward flexion increased by $8 \%$ as a result of the added helmet mass and inertia. Others ${ }^{45}$ have indicated that the mass of the helmet added to the head can increase the strain at the craniocervical junction. If, through further research, neck tension is found to be a biomechanical predictor of concussion, helmet and equipment manufacturers could use this information to optimise helmet performance and also to develop alternative methods of protecting against concussion.

There are several limitations of this study that should be noted. The case study is limited since only two cases were reconstructed. However, the reconstruction of these two cases may help shed some light on a potential mechanism of concussion since they investigated impacts that were primarily to the chest. This case study was performed using the Hybrid III ATD in a laboratory test environment. The Hybrid III headform and neck provide a biofidelic response in the loading condition analysed; however, it is not human, therefore tissue-level strains could not be directly assessed. The data acquired were used in conjunction with FE modelling to estimate the stretch in the upper cervical spine and a coupling ratio was applied to assess the strain in the CNS under these loading conditions. There are limited data that discuss spinal cord coupling ratio. However, the relative length of the spinal cord and brainstem when compared with C1-C5 also supports a coupling ratio of approximately 0.65 (online supplementary figure S4).

In case A, on impact, the torso's forward motion stopped and the player's head and helmet continued to move and flex forward. This indicates that the primary contact was to the chest of the struck player. Due to the severity of this collision, the bottom of the struck player's facemask appears to have made contact with the top of the defending player's helmet as his head flexed forward.

Table 3 Estimates of strain in the spinal canal (FE study) and CNS (FE study $\times 0.65$ spinal cord coupling ratio) for various neck tension loads and flexion angles of rotation. The estimates were applied to the laboratory reconstruction data to estimate the strain in the CNS of these injured players

\begin{tabular}{|c|c|c|c|c|c|c|c|c|c|c|c|c|}
\hline \multirow{4}{*}{ Case } & \multicolumn{5}{|c|}{ Tension } & \multicolumn{5}{|l|}{ Flexion } & \multicolumn{2}{|l|}{ Sum } \\
\hline & \multirow[t]{2}{*}{ Force } & \multicolumn{2}{|c|}{$\begin{array}{l}\text { Average strain } \\
\text { C1-C5 }\end{array}$} & \multicolumn{2}{|c|}{$\begin{array}{l}\text { Maximum strain } \\
\text { C1-C2 }\end{array}$} & \multirow[t]{2}{*}{ Rotation } & \multicolumn{2}{|c|}{$\begin{array}{l}\text { Average strain } \\
\text { C1-C5 }\end{array}$} & \multicolumn{2}{|c|}{$\begin{array}{l}\text { Maximum strain } \\
\text { C1-C2 }\end{array}$} & \multirow{2}{*}{$\begin{array}{l}\begin{array}{l}\text { Average strain } \\
\text { C1-C5 }\end{array} \\
\text { CNS }\end{array}$} & \multirow{2}{*}{$\begin{array}{l}\text { Maximum strain } \\
\text { C1-C2 } \\
\text { CNS }\end{array}$} \\
\hline & & $\begin{array}{l}\text { Spinal } \\
\text { canal }\end{array}$ & CNS & $\begin{array}{l}\text { Spinal } \\
\text { canal }\end{array}$ & CNS & & $\begin{array}{l}\text { Spinal } \\
\text { canal }\end{array}$ & CNS & $\begin{array}{l}\text { Spinal } \\
\text { canal }\end{array}$ & CNS & & \\
\hline & (N) & (\%) & (\%) & $(\%)$ & (\%) & $\left({ }^{\circ}\right)$ & (\%) & (\%) & (\%) & (\%) & (\%) & $(\%)$ \\
\hline FE study & 500 & 2.4 & 1.6 & 2.1 & 1.3 & 35 & 7.4 & 4.8 & 9.8 & 6.4 & - & - \\
\hline FE study & 1500 & 7.1 & 4.6 & 9.2 & 6.0 & 45 & 9.5 & 6.1 & 12.6 & 8.2 & - & - \\
\hline FE study & 2500 & 10.5 & 6.8 & 16.9 & 11.0 & 55 & 11.6 & 7.5 & 15.4 & 10.0 & - & - \\
\hline Case A & 2646 & 11.5 & 7.5 & 17.3 & 11.2 & 51 & 10.7 & 7.0 & 14.3 & 9.3 & 14.4 & 20.5 \\
\hline Case B & 1342 & 5.9 & 3.8 & 8.7 & 5.7 & 46 & 9.7 & 6.3 & 12.9 & 8.4 & 10.1 & 14.1 \\
\hline
\end{tabular}

CNS, central nervous system; FE, finite element. 
This was also simulated in our laboratory reconstruction of the collision and appears to have reduced the forward flexion of the head and increased the neck tension in comparison to test series 1 .

In this study, only strain in the neck has been considered from an impact to the chest. The rate of loading indicates the strain rate effect may be a factor in concussion and deserves further attention in the future. Additional limitations are discussed in the online supplementary video 1 .

Acknowledgements The authors would like to thank the staff of McCarthy Engineering Inc. for their assistance in various aspects of testing and preparation of this paper. Specifically, Mr. John Herbert, who constructed test fixtures and assisted in carrying out the testing; Mr. Brian Gilbert, who conducted the video analysis for Case A and Case B; Mrs. Pam Savage for assistance in preparation of the manuscript; and Mrs. Ann Kristo for her proofreading. Thank you to Dr. King Yang, Dr. Xin Jin, and Mr. Rohit Raut, of Wayne State University, for not only providing the GHBMC finite element model for this research but also for its segmentation.

Contributors RJ, DCV and JRM designed the test matrix for this research. RJ generated documentation for Wayne State University Institutional Review Board, conducted the laboratory impact testing, analysed and summarised the data and conducted finite element simulations. RJ, DCV and AIK reviewed the data and conducted the analysis. All authors contributed to this manuscript, its review, and approved the final version.

Funding Funding for this research has been received from McCarthy Engineering and from the Institute for Injury Research.

Competing interests None declared.

Patient consent Not required.

Ethics approval This study has been reviewed by the Wayne State University Institutional Review Board and it was determined that an IRB review was not required (HPR determination number 2017-51).

Provenance and peer review Not commissioned; externally peer reviewed. Data statement No additional data are available.

Open access This is an open access article distributed in accordance with the Creative Commons Attribution 4.0 Unported (CC BY 4.0) license, which permits others to copy, redistribute, remix, transform and build upon this work for any purpose, provided the original work is properly cited, a link to the licence is given, and indication of whether changes were made. See: http://creativecommons.org/ licenses/by/4.0

\section{REFERENCES}

1. McCrory P, Meeuwisse WH, Aubry M, et al. Consensus statement on concussion in sport: the 4th International Conference on Concussion in Sport held in Zurich, November 2012. Br J Sports Med 2013;47:250-8.

2. Friede RL. Specific cord damage at the atlas level as a pathogenic mechanism in cerebral concussion. J Neuropathol Exp Neurol 1960;19:266-79.

3. Friede R. The pathology and mechanics of experimental cerebral concussion. Wadd Technical Report, 1961: 61-256.

4. Ommaya AK, Hirsch A, Martinez J. The role of whiplash in cerebral concussion. Proc 10th Stapp Car Crash J 1966;10:314-24.

5. Hodgson VR. Tolerance of the head and neck to -Gx inertial loading of the head. Wright Patterson Air Force Base, 1981.

6. Stapp JP. Human tolerance to severe, abrupt acceleration. Gravitational Stress in Aerospace Medicine, 1951: 165-88.

7. Hutchinson MG. Concussions in the National Hockey League (NHL): The Video Analysis Project [PhD Dissertation]. University of Toronto, 2011.

8. King Al, Nakhla SS, Mital NK. Simulation of head and neck response to $-G x$ and $+G z$ impacts., AGARD Conf No, 253, Models and
Analogues for the Evaluation of Human Biodynamic Response, Performance and Protection, 1979.

9. Ommaya AK. Trauma to the nervous system. Hunterian Lecture delivered at the. England: Royal College of Surgeons, 1965: 317-47.

10. Jadischke R, Viano DC, McCarthy J, et al. The effects of helmet weight on Hybrid III head and neck responses by comparing unhelmeted and helmeted impacts. J Biomech Eng 2016;138:101008

11. Pellman EJ, Viano DC, Withnall C, et al. Concussion in professional football: helmet testing to assess impact performance--part 11. Neurosurgery 2006;58:78-95.

12. Pellman EJ, Viano DC, Tucker AM, et al. Concussion in professional football: reconstruction of game impacts and injuries. Neurosurgery 2003;53:799-814.

13. Viano DC, Withnall C, Halstead D. Impact performance of modern football helmets. Ann Biomed Eng 2012;40:160-74.

14. Fice JB, Cronin DS, Panzer MB. Cervical spine model to predict capsular ligament response in rear impact. Ann Biomed Eng 2011;39:2152-62.

15. Mao H, Zhang L, Jiang B, et al. Development of a finite element human head model partially validated with thirty five experimental cases. J Biomech Eng 2013;135:111002.

16. Smith CG. Changes in length and position of the segments of the spinal cord with changes in posture in the monkey. Radiology 1956;66:259-66.

17. Yuan Q, Dougherty L, Margulies SS. In vivo human cervical spinal cord deformation and displacement in flexion. Spine 1998;23:1677-83.

18. Kroeker SG, Ching RP. Coupling between the spinal cord and cervical vertebral column under tensile loading. J Biomech 2013;46:773-9.

19. Maiman DJ, Coats J, Myklebust JB. Cord/spine motion in experimental spinal cord injury. J Spinal Disord 1989;2:14-19.

20. Dvorak J, Panjabi MM, Novotny JE, et al. In vivo flexion/extension of the normal cervical spine. J Orthop Res 1991;9:828-34.

21. Yliniemi EM, Pellettiere JA, Doczy EJ, et al. Dynamic tensile failure mechanics of the musculoskeletal neck using a cadaver model. $J$ Biomech Eng 2009;131:051001.

22. Yliniemi EM. Dynamic tensile neck injury: a post mortem human study. Seattle, WA: University of Washington, 2005.

23. Singh A, Kallakuri S, Chen C, et al. Structural and functional changes in nerve roots due to tension at various strains and strain rates: an in-vivo study. J Neurotrauma 2009;26:627-40.

24. Sances A, Myklebust J, Cusick JF. Experimental studies of brain and neck injury. 25th Stapp Car Crash Conf, 1981.

25. Breig A. Biomechanics of the central nervous system. Almqvist and Stockholm, Sweden: Wiskell, 1960.

26. Denny-Brown D, Russell WR. Experimental cerebral concussion. Brain 1941;64(2-3):93-164.

27. Endo $\mathrm{K}$, Suzuki $\mathrm{H}$, Nishimura $\mathrm{H}$, et al. Kinematic analysis of the cervical cord and cervical canal by dynamic neck motion. Asian Spine J 2014;8:747-52.

28. Kuwazawa Y, Pope MH, Bashir W, et al. The length of the cervical cord: effects of postural changes in healthy volunteers using positional magnetic resonance imaging. Spine 2006;31:E579-83.

29. Margulies SS, Meaney DF, Bilston LB, et al. In vivo motion of the human cervical spinal cord in extension and flexion. Proc IRCOBI 1992;20:213-24.

30. Mertz HJ, Patrick LM. Investigation of the kinematics and kinetics of whiplash. Proc. 11th Stapp Car Crash Conf, 1967: 175-206.

31. Mertz HJ, Patrick LM. Strength and response of the human neck Proc. 15th Stapp Car Crash Conf, 1971.

32. Thunnissen J, Wismans J, Ewing CL. Human volunteer head-neck response in frontal flexion: a new analysis. Proc. 39th Stapp Car Crash Conf, 1995: 439-60.

33. Viano DC, Casson IR, Pellman EJ. Concussion in professiona football: biomechanics of the struck player--part 14. Neurosurgery 2007;61:313-28

34. Chancey VC, Nightingale RW, Van Ee CA, et al. Improved estimation of human neck tensile tolerance: reducing the range of reported tolerance using anthropometrically correct muscles and optimized physiologic initial conditions. Stapp Car Crash J 2003;47:135-53.

35. Yoganandan N, Pintar FA, Maiman DJ, et al. Human head-neck biomechanics under axial tension. Med Eng Phys 1996;18:289-94

36. Hodgson VR, Thomas LM. Acceleration induced shear strains in a monkey brain hemisection. Proc. 23rd Stapp Car Crash Conf, 1979: 589-611. 